\title{
Empirical Analysis on the Limits of Violence and Public Power Based on the Maximum Limits Algorithm
}

\author{
Jingfang Zheng \\ School of Law, Xiamen University, Xiamen, China \\ Department of Law, Minjiang University, Fuzhou, China \\ zh_engjingfang@126.com
}

Keywords: incremental network; feasibility vector; statistical curve; legitimacy; maximum limits algorithm; mathematical modeling

\begin{abstract}
With the social standard value has become more apparent in the contemporary civil law, the individual private interest in special civil relations of marriage and family is impossible to implement an absolute protection, it needs state intervention, that is public power intervention. This paper studies legitimacy of public power that intervenes in domestic violence comprehensively and comparatively, through analysing historical document, building the necessity and feasibility model of national public power that intervenes in domestic violence by using mathematical modeling ideas, exploring the conditions and limits of national public power that intervenes in domestic violence cases by using maximum algorithm, it finally comes to a conclusion that public power intervening in domestic violence reflects social and legal progress and also is an urgent need of protecting vulnerable groups.
\end{abstract}

\section{Introduction}

Family is the important cell of society, family harmony relates to the stability of society and the progress of civilization. Domestic violence is a ubiquitous and serious social problem, including our country[1]. Traditionally, family is the fortress of individual rights and the barrier of individual security and peace. Countries should respect autonomy in some degree, bring the public law order and social security, welfare property protection of vulnerable groups and altruistic tendency into relation of rights and obligation. There is an obvious boundaries between public law and private law, private autonomy area and public power exercised area, it is the basis of legal thought in classical period[2]. In the view of legal realism, there isn't an obvious boundaries between public and private. The boundary between public law and private law, public power exercised area and private autonomy area is not constant and absolute but mobile and live, and is rapidly forming some middle areas with the characteristics of two areas between public law and private law. At present, the issue of public power interning in domestic violence has attracted many scholars' attention. For example: Lv chunjuan introduced status quo of domestic violence prevention and problems existed in China, and based on the experience of domestic violence prevention in America and Chinese Taiwan area, put forward countermeasures and suggestions toward improving domestic violence prevention in China at an essay named The prevention of domestic violence-- from the prospective of national public power intervention; Wang Guozhen and Song Hai'ou put forward that domestic violence has always been considered as a filed that public power should try to avoid because of the particularity of the relationship between the subject of violence, but it can be seen that public power intervening in domestic violence is necessary from the serious harmfulness of domestic violence at an essay named Analysis of the character of public power in domestic violence prevention. Tian Mei put forward the principles that should be followed for improving legal system through the meaning of domestic violence and the introspection on the status quo of police intervention, and from four angles, that is coordinating contradiction as a fundamental, forensics work as an emphasis, positive intervention combined with limited intervention as a way and protecting responsibility under extremely dangerous as a exception at the essay named[3]. The principle research of police intervenes in domestic violence legal system improvement. Fu Qingtao introduced that on the one hand, domestic violence violates human rights, it is an abuse of power, and it has public domain character, police 
should intervene. One the other hand, domestic violence is different from general violence, its private autonomy character makes police should not intervene at the essay named Discuss on the limit issues of policy power intervening in domestic violence.

\section{The Analysis of the Legitimacy of National Public Power Intervening in Domestic Violence}

People have had a strong resistance against the violence of marital prosecution or other intimate relationships since ancient times. Domestic violence is considered as a kind of private matter for a long period time. But this conflicting phenomenon has a urgent new ideas, further causes landmarks of change in the legislature, police, procuratorial and judicial organs in attitudes.

A. The attention of western countries national power toward domestic violence

Over the past two decades, those western countries where feminist movement is popular has a significant development and breakthrough on no matter in the field of basic theory or criminal legislation and justice policies towards the cases of countries intervening domestic violence[4]. The following set America as an example, introduces the history of public power intervening domestic violence. As Figure 1 shown.

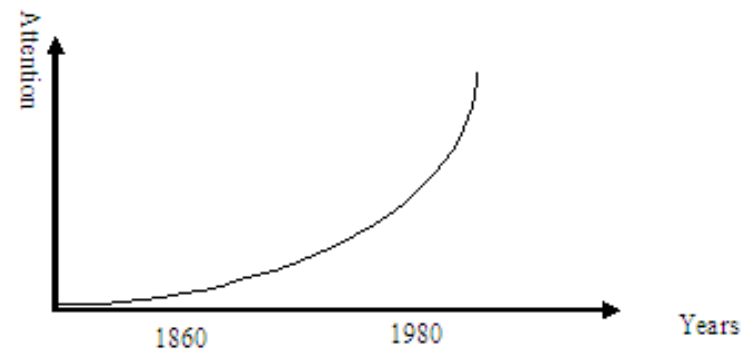

Figure 1. The History of Public Power Intervening Domestic Violence

As can be seen from Figure 1, domestic violence did not get attention before 1860s, but American public power had been gradually improved and constantly intervened in domestic violence since then until the end of 1980s, to protect people's legitimate rights and interests through laws and regulations. The attention of child abuse is highest in these regulations, Figure 2 gives several forms of child abuse:

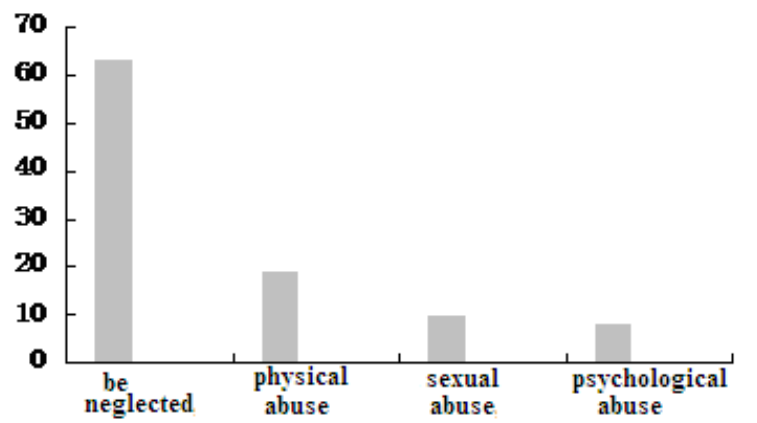

Figure 2. $\quad$ Several Forms of Children Abuse

As can be seen from Figure2, there is $63 \%$ of child abuse is ignored, $19 \%$ suffer from physical abuse, $10 \%$ suffer from sexual abuse, $8 \%$ children suffer from psychological abuse. The relativity of European Human Rights Act Section 3 that is inhuman and degrading treatment is verified in many cases that against children domestic violence directly, therefore children protection is given much attention in America.

B. The attention of public power for domestic violence in China

China's anti-domestic violence legislation took Beijing Fourth World Conference on Women in 1995 as an opportunity, paving ways for local legislation against domestic violence, A certain number of regulations about preventing and restraining domestic violence that was approved by Hunan Changsha Municipal Office , the Municipal People's Government Office jointly, it is the first local regulation against domestic violence. Marriage Law (Revise Version) which was published in 2001 brought the clause about domestic violence into it in the national legislative level for the first time, made regulations on the issue of domestic violence fist, and put police into domain of marriage 
and family. A certain number of opinions about preventing and restraining domestic violence issued by The national women's federations and other seven ministries jointly on July 31, 2008, it was a concrete reflection of treating local successful experience as national normative document.

\section{The analysis of mathematical model necessity and feasibility}

Man that is entitled to the right of exercising violence against his wife since ancient times. This is the important reason of traditionally police playing the role of mediating negatively. Subsequently, countries increase the right protection of human as an independent individual, the theory of family autonomy and power first met with challenges and lash. Family autonomy or respect for the family under traditional model is actually distorted, it comes at the expense of sacrificing women and children's rights and interests. Domestic violence has become a public crime, its damage has already beyond the scope of family relations and it is harmful to society, country has responsibility to intervene positively. Using the following mathematical model to discuss the necessity and feasibility of national public power intervenes in domestic violence.

Assume that there are $\mathrm{N}$ kinds of main factors that have an impact on national public power intervening in family violence, and M secondary causes, set $t_{i j}$ as the influence coefficient, set $t_{i j}$ as the influence of I kind of factor in $\mathrm{N}$ kinds of main factors, according to the definition comes $t_{i j}=X_{i j} / X_{j}(1 \leq i, j \leq 3)$

plug (1) into $X_{i}=X_{i 1}+X_{i 2}+X_{i 3}+d_{i}(i=1,2,3)$, then can get[5,6] :

$$
X_{i}=t_{i 1} X_{1}+t_{i 2} X_{2}+t_{i 3} X_{3}+d_{i}(i=1,2,3) \text {. }
$$

Set $T=\left(t_{i j}\right)$, introduce the necessity vector and feasibility vector respectively[7]:

$x=\left(x_{1}, x_{2}, x_{3}\right)^{T}, d=\left(d_{1}, d_{2}, d_{3}\right)^{T}$

Equation (2) can be wrote as matrix form $x=T x+d$

or

$$
(I-T) x=d
$$

Set

$$
A=I-T
$$

Equation (2) finally becomes $A x=d$

Set ${ }^{T=\left(t_{i j}\right)}$ as various factors are the square matrix of non - negative real number, when $\|T\|_{1}<1$ or $\|T\|_{\infty}<1$ is right, so exists inverse matrix of $I-T$ and the elements are negative.

Because of $(I-T)\left(I+T+T^{2}+\cdots+T^{k}\right)=I-T^{k+1}$,

The norm of $\mathrm{T}$ is less than $1, T^{k} \rightarrow 0(k \rightarrow \infty)$, set $\mathrm{K}$ in both sides of equation (3) tends to infinite, then comes $(I-T) \cdot \sum_{k=0}^{\infty} T^{k}=1$

that is $(I-T)^{-1}=\sum_{k=0}^{\infty} T^{k}$

From the above functions can be obtained that each element is negative, proved the necessity and feasibility of the national public power intervening in domestic violence.

From the angle of realism, the wealthiness of a country can give victims or children of domestic violence mental and physical help. The support and service to victims has to be emphasized, such as emergency shelter is critical to our entire intervention project[8].Traffic, food and money always offered by these organizations; some shelters even help people to find new job and house. All of effective implementations of these strategies need the financial help from federal, state and local government.

\section{The emprical the analysis based on the conditions and limits of maximum algorithm}

National public power has the necessity and feasibility in intervening in domestic violence cases. Then, is there any need of premise and limit to the intervention of public power? From the 
perspective of the history of country and family relations, public power and private power are a process of wrestling, both can not be ignored. The Supreme Judicial Court defines this power as a power to impose restrictions on private power for maintaining public order, security, ethnics and public welfare. Certainly, power is bound with corruption, if public power is expanded infinitely, while the scope of family autonomy is limited and reduced constantly, it will turn into totalitarianism, will damage the rights of family and individuals[9]. This will be a human disaster.

Through the following mathematical model can research the limit issue of national public power intervening in domestic violence. A estimate about the limit upper bound of national public power intervening in domestic violence, that is

$$
v \leq c[P, \bar{P}]
$$

Set $P$ is one of a subset of maximum limit set $N$ in set $G=(N, A)$, minimum limit $s \in P$, maximum limit $s \notin P$, the complementary set of $\mathrm{P}$ is $\bar{P}=N / P$, its capacity $c[P, \bar{P}]_{\text {defined as the }}$ sum of all arcs of $[P, \bar{P}]$. That is to say[10]:

$$
\begin{gathered}
\mid P, \bar{P}\rfloor=\{(i, j) / i \in P, j \in P,(i, j) \in A\} \\
c \mid P, \bar{P}]=\sum_{(i, j)}\{c(i, j) /(i, j) \in[P, \bar{P}]\}
\end{gathered}
$$

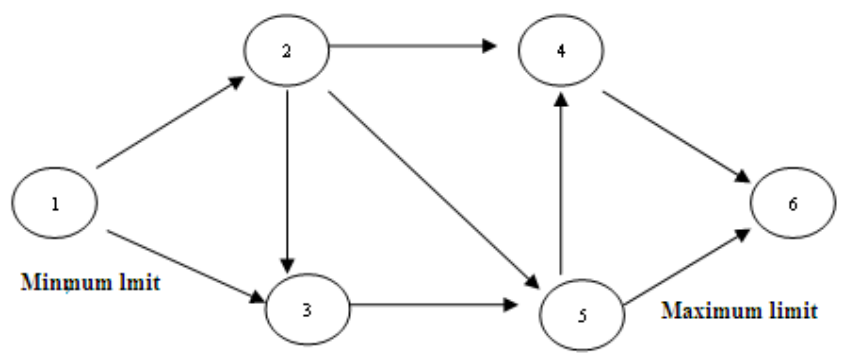

Figure 3. The mathematical model of the limit issue of national public power intervening in domestic violence

Set Figure 3 as an example, minimum limit is $s=1$, maximum limit is $s=6$, put s.t. $\sum_{j}\{f(i, j) /(i, j) \in A\}-\sum_{j}\{f(j, i) /(j, i) \in A\}=0, \forall i \neq s, t$, add all $i \in P /\{s\}$ to (4), then add below equation $\sum_{j}\{f(s, j) /(s, j) \in A\}-\sum_{j}\{f(j, s) /(j, s) \in A\}=v$ in all items $f(i, j)$ that added in left, $i, j \in P$ appeared twice, because of the opposite sign, it could be offset, then just left the item of $i \in P, j \in \bar{P}$, then it comes

$\sum_{(i, j)}\{f(i, j) / i \in P, j \in \bar{P},(i, j) \in A\}-\sum_{(i, j)}\{f(j, i) / i \in P, j \in \bar{P},(j, i) \in A\}=v$ following steps

Maximum limit algorithm consists of the

(1) select a initial flow f, set $f(i, j)=0$ for all $(i, j) \in A$;

(2) build $G=(N, A)$, relative to increment network $G^{`}$ (f) of f;

(3) find the route $t$ of minimum limit $s$ to maximum limit $t$ on increment network $G^{`}(f)$, if this route doesn't exist, then turn to (4), if find a way ${ }^{\mu}$ from s to t, using $\delta$ to represent the minimum value of all capacity $C^{\prime}(\bullet, \bullet)$ on $\mu, \delta$ is called as the increment of network flow, using $\mu_{\text {to revise }}$ network flow, as follows :

When forward direction $(i, j) \in \mu, f(i, j):=f(i, j)+\delta$

When reverse direction $(i, j) \in \mu, f(i, j):=f(i, j)-\delta$

After revising f turn to step

(1)set $\mathrm{f}$ as maximum value

According to above mentioned that the principle of building two arcs or one arc of every arc in $\mathrm{G}=(\mathrm{N}, \mathrm{A}), \mathrm{G}$ relative to the increment network G'(f) of f, as Figure 4 shown, reverse direction arcs are represented by dotted lines, forward direction arcs are represented by the rest, all numberals beside arcs represent the capacity $C^{(\bullet, \bullet)}$ in $\mathrm{G}^{\prime}(\mathrm{f})$, it is actually the limit value of when revising $\mathrm{f}$ 


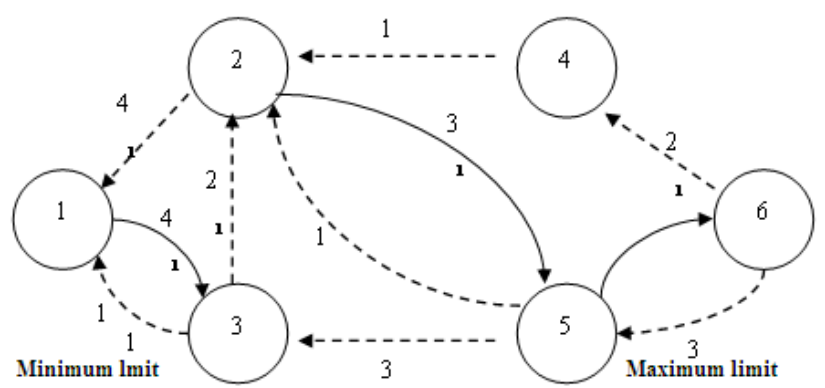

Figure 4. The increment network G'(f) of $\mathrm{f}$

Now it makes a further elaboration for the discussion on above examples, from network flow $\mathrm{f}$ of any conforming equation (4), every times comes to step (2) (3), make limit value increase a unit, this process must end in a finite times, when it comes to step (4), then can build a set of limit value $[P, \bar{P}]$ accordingly, make $v(f)=c[P, \bar{P}]$. By the time the limit value is maximal, that is to say that the limit of national public power intervening in domestic violence can not beyond this value.

\section{Conclusion}

National public power intervening in domestic violence is a right limit to violence perpetrators, according to modern legal spirit, this kind of limitation should be the necessity to limit, and should try to avoid be abused at the same time. The best way to solute this issue is legislative stipulation expressly, that is stipulated applied situation and measures precisely by law, non expressly provided by law shall not apply. In order to achieve the protection of victims' rights, but not to violate the rights of violence perpetrators.

\section{References}

[1] Lv Chunjuan. The Prevention of Domestic Violence--from the Perspective of National Public Power Intervention. The Journal of National School of Administration,2011(4):44-49.

[2] Wang Guozhen, Song Hai'ou. The Analysis of the Character of Public Power in Domestic Violence Prevention,Chuancheng, 2009(1):35-39.

[3] Tian Mei. The Principle Analysis of Police Intervening in Domestic Violence Legal System Improvement,Qianyan,2010(6):108-112.

[4] Fu Qingtao. Discuss on the Limit Issues of Policy Power Intervening in Domestic Violence. Journal of Jiangxi public security College,2012(4):79-83.

[5] Zhang Ti. Against Domestic Violence to Protect Womens' Legitimate Rights and Interests -from the Prospective of Improving Womens' social security. Journal of Liaoning Police Justice Management Institute.,2009(01):85-89.

[6] Chen Min. Thoughts Concerning Diffculties about Affirming Domestic Violence. Application of Law,2009(02):11-15

[7] Jiang Hong. The Analysis of Formulating the Specification of Police Preventing Domestic Violence, Journal of Chang'an University,2009(02):67-69.

[8] A·B·Resolwa. American Domestic Violence Research and Social Policy. Foreign Society and Science, 2007(01):122-126.

[9] Rong Weiyi, Song Meiya. Against Domestic Violence to Women in Family. China Social Sciences Press,2002:457.

[10] Du Jiangyong. Family Autonomy, Nation Intervention and Marriage System Legislation in China, Journal of Guangxi University for Nationalities (Philosophy and Social Sciences), 2010.(4):148. 